\section{Management of Associated Rheumatoid Arthritis and Fibromyalgia}

\section{To the Editor:}

The interesting report of Coury and colleagues ${ }^{1}$, and thoughtful accompanying editorial by Mäkinen and Hannonen ${ }^{2}$, call attention to the important problem of fibromyalgia (FM) in patients with rheumatoid arthritis (RA).

Patient self-report questionnaire data for pain, fatigue, or patient global estimate, the patient measure that is included in the DAS28 ${ }^{3}$, are usually high in patients with FM or FM and RA. The self-report scores often appear to health professionals disproportionately high in patients with FM and RA relative to "objective" data from a joint examination or laboratory tests. For example, Coury, et al ${ }^{1}$ suggest that "DAS28 overestimates the true status of patients with RA who also have FM" (emphasis added by this author).

An alternative approach is to regard anything written or reported by a patient as "true," although the response may suggest higher levels of inflammatory activity than might be present. Apparently disproportionately high scores, as interpreted by the clinician, in patients who might have FM or FM and RA or another rheumatic disease might be regarded as a clue in diagnosis. This approach is reflected in the January 2009 issue in an article by Wolfe, et al on complexities in evaluation of systemic lupus erythematosus (SLE) activity in patients with both FM and SLE ${ }^{4}$.

We have reported 3 phenomena regarding self-report responses on a multidimensional health assessment questionnaire (MDHAQ) $)^{5}$ in patients with FM: a high ratio of pain to functional disability scores ${ }^{6}$, a high ratio of fatigue to functional disability scores ${ }^{7}$, and a high number of symptoms on a review of systems ${ }^{7}$. These measures appear as effective as a sedimentation rate to distinguish patients with RA from patients with $\mathrm{FM}^{6,7}$. We did not report on patients with RA and FM, but subsequent clinical experience has indicated particular value in patients with FM who meet criteria for RA or another rheumatic disease.

The reported "clues" certainly are not $100 \%$ diagnostic, as is the case with all rheumatology measures. For example, a substantial rise in erythrocyte sedimentation rate in a patient with RA may indicate an infection or lymphoma, rather than a disease flare. All rheumatology measures, including laboratory tests and patient questionnaire responses, require interpretation by a thoughtful and caring clinician.

All the measures reported as "clues" to FM are included on the simple one-page $\mathrm{MDHAQ}^{5}$. FM is primarily a patient-reported syndrome, and patient self-report appears a most effective way to identify patients, partic- ularly patients who meet criteria for concomitant inflammatory diseases, such as RA and SLE. We continue to advocate routine use of the MDHAQ ${ }^{8}$ at all visits of all patients seen by a rheumatologist.

THEODORE PINCUS, MD, New York University Hospital for Joint Diseases, 301 East 17th Street, New York 10003, New York, USA. Address correspondence to Dr. T. Pincus; E-mail: tedpincus@gmail.com

\section{REFERENCES}

1. Coury F, Rossat A, Tebib A, et al. Rheumatoid arthritis and fibromyalgia: a frequent unrelated association complicating disease management. J Rheumatol 2009;36:58-62.

2. Makinen $\mathrm{H}$, Hannonen P. How to assess patients with rheumatoid arthritis and concomitant fibromyalgia? [editorial]. J Rheumatol 2009;36:9-11.

3. Prevoo MLL, van 't Hof MA, Kuper HH, van Leeuwen MA, van de Putte LBA, van Riel PLCM. Modified disease activity scores that include twenty-eight-joint counts: Development and validation in a prospective longitudinal study of patients with rheumatoid arthritis Arthritis Rheum 1995;38:44-8.

4. Wolfe F, Petri M, Alarcon GS, et al. Fibromyalgia, systemic lupus erythematosus (SLE), and evaluation of SLE activity. J Rheumatol 2009;36:82-8

5. Pincus T, Sokka T, Kautiainen H. Further development of a physical function scale on a multidimensional Health Assessment Questionnaire for standard care of patients with rheumatic diseases. J Rheumatol 2005;32:1432-9.

6. Callahan LF, Pincus T. The P-VAS/D-ADL ratio: A clue from a self-report questionnaire to distinguish rheumatoid arthritis from noninflammatory diffuse musculoskeletal pain. Arthritis Rheum 1990;33:1317-22.

7. DeWalt DA, Reed GW, Pincus T. Further clues to recognition of patients with fibromyalgia from a simple 2-page patient multidimensional Health Assessment Questionnaire (MDHAQ). Clin Exp Rheumatol 2004;22:453-61.

8. Pincus T, Yazici Y, Bergman M. Saving time and improving care with a multidimensional Health Assessment Questionnaire: 10 practical considerations. J Rheumatol 2006;33:448-54.

J Rheumatol 2009;36:9; doi:10.3899/jrheum.090336 